\title{
Partial Shading, Effects and Solution for Photovoltaic String: A Review \\ ${ }^{* 1}$ Pankaj Sawarkar, ${ }^{2}$ Sanjay Bodkhe, ${ }^{3}$ Minakshi Bopche, ${ }^{4}$ Praful Kumbhare, ${ }^{5}$ Vaishanavi Deshpande \\ ${ }^{1,2}$ Shri Ramdeobaba College of Engineering and Management, Nagpur \\ ${ }^{3}$ Novasys Greenergy Pvt. Ltd., Nagpur \\ ${ }^{4}$ Guru Nanak Institute of Engineering and Technology, Nagpur \\ ${ }^{5}$ J.D.College of Engineering \& Management, Nagpur \\ Email:sawarkarp@rknec.edu,bodkhesb@rknec.edu,bopchemu@rknec.edu,praf369@gmail.com, vaishnavidhok11@gmail.com
}

Received: 20th November 2019, Accepted: 31st January 2020, Published: 30th April 2020

\begin{abstract}
The energy which is generated from natural resources that are abundantly available in nature is called Nonconventional energy sources. Light energy from sun, current of air, storage of water at hilltop, water movement inside sea, heat inside earth is the example of Non-conventional energy sources, etc. The solar energy is based on the conversion of sun rays into electrical voltage and current and it is the single-stage conversion of radiation into electricity. The photovoltaic (PV) power generation is a phenomenon in which photons from sun rays collide on PN junction of semi-conductor material and generates electrical energy. This solar power system uses the string of solar panels distributed over large areas. Power generated by these strings is affected by shadow initiated from different causes. The effect of these shadows is to reduce the power generated by the photovoltaic system. This paper explains the various effect of shadow on PV system and summarizes the different methods for improving the PV performance under shadow conditions. It also covers a wide review of the trends and state-of-art techniques indicated through research to curb the effects of partial shading.
\end{abstract}

Keywords

Solar Photovoltaic System, Bypass Diode, MPPT, Partial Shading, Topology, Reconfiguration.

\section{Introduction}

Amongst different non-conventional energy sources, photo-voltaic (PV) energy is an abundant and clean alternative for electrical power generation. It provides a number of benefits such as free fuel, flexible in terms of generation and requirement, low running cost, etc.[1-4]. Electrical Power generation by this technology can support to reduce environmental pollution and also a reduction in the consumption of conventional fuels. The solar insolation, atmospheric temperature, array configuration, and shading due to surrounding objects influence the performance of PV system. The momentary or constant shading on PV panel due to a passing cloud or neighboring objects not only causes energy loss in the conversion but also creates non-linearity on the I-V characteristics of PV system. [5]

The component of solar power generating systems are solar modules that convert solar radiations into electrical energy, power electronics grid inverter which converts dc electrical power into alternating electrical power. This grid inverter is interfacing device in-between grid and dc solar system. When a number of solar panels (modules) are connected in series it is called as solar string (array). The number of panels depends upon the system voltage requirement and such strings are connected in parallel to increase the current capacity of the whole system. Since all the modules are connected in series each module contributes to string voltage \& also contributes to current. As they are connected in series the current generated by each module should be same but due to shadow effect the affected module may not do so. When the modules in the string experience multiple irradiation intensities, their generated power gets reduced [5-6]. If shading exists on the PV string, power output generated from string gets reduced. When one or more PV modules are in different operating conditions and operating with their individual maximum power points (MPPs) such a situation is called as (I-V) characteristics mismatch [6-7] and due to this mismatch there is a reduction in electrical power output of the by entire PV string. If anyone module of a PV array comes under shadow then that particular shaded module will be in reverse bias, which leads to power loss in the entire string. The bypass diode is a solution for avoiding this condition of the module. The bypass diodes are connected in anti-parallel with each module which bypasses the module during shadow period but it creates additional loss due to their ON state resistances during conduction [8]. The array topology defines the connection of different modules installed in different rows \& columns. Different connections used in PV systems are Series-Parallel (SP), Total Cross Tied (TCT) and Bridge Linked (BL) [9-10].

In a PV string, current generated by the whole string is decided by the shading on the panels. The mostly shaded panel limits the current generated by the entire array. Various methods have been in literature to minimize effect. 
This paper collected multiple solutions for improving the performance of solar string under the shaded conditions. These available methods can be categorized into two methods. The first one is based on the change in module configuration and the second category is by using power electronics circuits. This paper is further divided into four sections, i.e. section II: describes the classical methods for the performance improvement of solar string. Section III: describes the use of different power electronics circuits for the same objective. Section IV describes Adaptive PV array re-configuration \& in section V all the techniques were compared on the bases of reliability, maintenance, \& performance.

\section{PV System Description:}

The total number of modules in a solar PV system depends upon the rated output power. Each PV module consists of a series-parallel connection of silicon wafers. These silicon wafers are made up of p-type and n-type semiconductor materials. When p-type and n-type semiconductor material comes together there will be the formation of junction called a depletion layer. This combination of p-type and n-type is equivalent to semiconductor diode. The equivalent circuit of the wafer is shown in (Fig 1(A)) and its ideal I-V and P-V characteristics of PV wafer are shown in (Fig 1(B)).

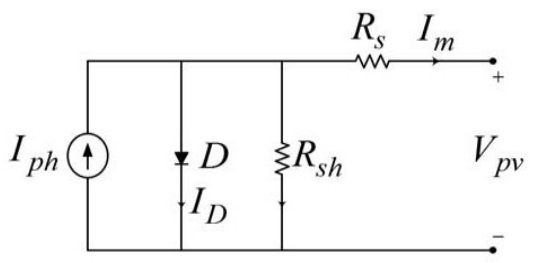

Fig 1(A): Equivalent Circuit of PV Wafer

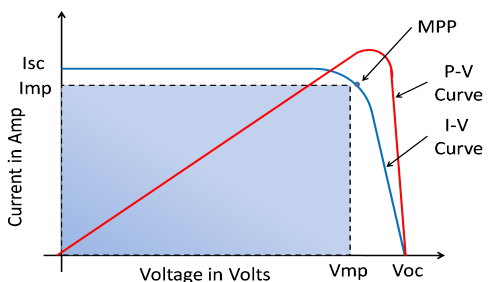

Fig 1(B): I-V and P-V Characteristics of PV Wafer

When partial shadow exists on PV string, the output of the entire string gets reduced, it also reduces the conversion efficiency of the system. Under this shadow condition, the position of maximum power point in the $\mathrm{P}-\mathrm{V}$ curve will be shifted to another point that is called local maxima. This shadow effect creates multiple maxima on $\mathrm{P}-\mathrm{V}$ curve and which is difficult for any device to attain. These losses can be reduced by altering topology, or by using passive elements like diode or by using active elements like active switches.

\section{Methodology}

To overcome the effect of partial shading different methodologies can be adopted. The simple bypass diode technique is the low-cost solution but increasing losses and reducing efficiency of module. Another method is by changing connection of modules with or without altering position and connection. By using active element i.e. MMPT, Inverter, DC-DC converter, the effect of partial shading can be reduced. Adaptive PV array reconfiguration is the dynamic reconfiguration of modules inside entire module metric for optimal generation. The different methodologies are discussed below.

\section{Topology}

The power generated by a solar power system under shading conditions can be maximized by altering its topology. Solar power modules can be configured with different topologies i.e. Series-Parallel (SP), Total Cross Tied (TCT), Bridge link (BL) configurations. [11] suggested that, if shadow covers the modules from bottom to top and left to right then, TCT topology is good solution and when the shadow is on the bottom leftmost module then SP configuration can be a good solution but if shadow progress is from left to right on bottom row of modules then anyone topology can be used. All topology produces the same power when bottom row is fully shaded. Due Su Do Ku configuration local maxima will be removed and only global maxima will be maintained in I-V characteristics of PV system suggested by [12].

(Fei Lu, at. al. 2013) suggested that the effect of partial shading can be minimized by changing the layout of solar wafers within the solar panel. By considering the standard panel of 72 wafers, wafers mapping can be done with following two arrangements.

As shown in fig 2. Fig 2(a) ) A standard 72 cell module with 3 bypass diodes, Fig 2(b) Configuration with a series of six matrices, each matrix consisting of two parallel strings of 12 halved cells, with 3 bypass diodes., Fig 2(c) Configuration with a series of 72 matrices, each matrix consisting of two halved cells in parallel, with 3 bypass diodes. 


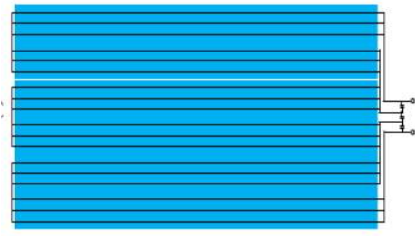

Fig. 2(A) A standard 72 cell module with 3 bypass diodes

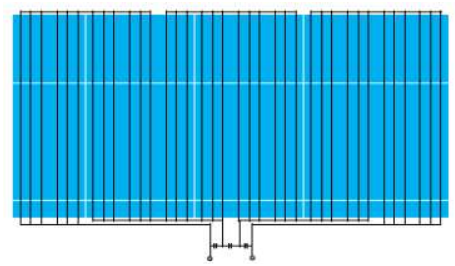

Fig. 2(B) Configuration with 12 halved cells, with 3 bypass diodes

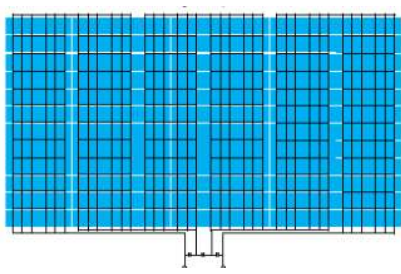

Fig. 2(C) Configuration with a series of 72 matrices, two halved cells with 3 bypass diodes

First Arrangement: 12 half wafers of standard size will be connected in series and such two strings will be connected in parallel. Such six groups will be connected in series with 3 bypass diodes.

Second Arrangement: 2 half wafer will be connected in parallel and such 72 groups will be connected in series in with three bypass diodes one panel.

Due to the use of halved wafer configurations with parallel paths, within the panel the performance under partial shading conditions will be improved and it is confirmed through simulation. But during panel assembly soldering issue will be increased.

Partially shaded modules can be utilized for accelerating power in partial shading conditions. In the topology, PV arrays are split into two groups i.e. fixed part and reconfigurable part. The modules in of fix part will nor be reconfigured but the other modules will be reconfigured on the bases of shading condition. This reduces the number of switches requirement for reconfiguration and also considerable reduction in partial shading losses any for $\mathrm{n} \times \mathrm{m}$ system.[14]

\section{Passive Element (Bypass Diode)}

In the PV generation system the power output is inversely proportional to number of shaded panels. In PV string all the solar panels are connected in series and carry same current during all the conditions. If shadow exists on any panel, that particular panel will increase its resistance and creates voltage drop phenomenon. This particular panel will be in reverse bias and reduces the string current and creates hot Spot condition. To overcome this phenomenon of reverse biasing and hot spot bypass diodes technique is introduced [13]. In the PV system, the numbers of modules are connected in series and every module is connected with bypass diode in reverse bias. When shadow covers any solar module then its bypass diode will start conducting. This diode carries the current generated by the whole string. This diode introducing power losses in the PV system and the bypass diodes (up to one diode for each cell) was proposed as a possible solution [15]. However, this approach has not encountered the favor of crystalline PV modules producers since it requires a not negligible technological cost and can be even detrimental in terms of power production, when many diodes are activated because of their power consumption discussed by [16]. By using proper mitigation of switches the performance of solar string can be improved as suggested by [17]. Even if this bypass diode is easy to implement but it created more losses in system and critical disadvantages of bypass diode is that it misleads the MPPT controller. [18-19].

\section{Active Elements:}

[20] suggested that, Partial shading scenarios can be analyzed by using shading rate and strength of shading. The shading strength and the maximum power point voltage of the PV can be estimated by a multiple-output support vector regression (M-SVR) technique. The maximum power point can be predicted from measured data and the system can be operated with best MPPT point. By using two drawbacks of power loss during shading can be minimized. The first MPPT is used to attain the occurrence of PSC and second stage MPPT with new algorithm that is based on ramp change of the duty cycle due to these two MPPT techniques the global maximum power point of array is reached accurately. The $\mathrm{P} \& \mathrm{O}$ algorithm is then re-activated to trace small changes of the new MPP[21]. When single MPPT is used for multiple strings, the MPP of healthy string also shifted to MPP of shaded string. This increases the amount of losses in the system. [22-23] suggested that, the problem can be solved by using distributed MPPT system. In distributed MPPT system each string is having its own MPPT which operated for common system voltage and current. In this technique only the MPPT of shaded string will operate and operation of other MPPT will be unaffected. [24-25] discuss the multilevel inverter topology can be used for individual string for improving performance under partial shading condition of string.

\section{Adaptive PV array reconfiguration.}

Adaptive PV array reconfiguration means the connection between modules will be continuously changed to get optimistic electrical power during shading conditions. In order to improve the power output under partial shading conditions, Adaptive PV array reconfiguration can be a good solution, The researcher has reported some findings by using different optimization techniques i.e. by using Particle Swarm Optimization, Scanning algorithm, Best and Worth Sorting Algorithm, Rough set theory, irradiance equalization principle, Well-known 
subset sum problem, Ant colony optimization technique etc. The reconfiguration can be done by shifting the modules from shade area to the un-shaded area without changing the electrical connection and another method is by shifting the shaded module from one string to another string by changing electrical connection. The position changing method is not feasible but connection changing method can be developed by using power electronics switches and controllers. The operation of these switches will be controlled by microcontroller and these microcontroller will operate these switches as per above-said techniques. This involves high number of power electronics switches. [26]

\section{Result and Discussion}

In this paper, different techniques were studied and it is found that if only a string of simple modules is used for power generation, it has to be dealt with hot spot issues during shading. For removing the effect of hot spot the use of bypass diode is suggested. If multiple bypass diodes are used in the system, it is reported that due to bypass diode power loss will be more. Some work is published on reconfiguration of modules with SP, TCT, $\mathrm{BL}$, Su Do Ko pattern, etc. This research indicates the performance of different reconfiguration will depend upon the progress of shadow over PV modules. Some researchers suggested use of power electronics circuits for reducing the effect of partial shading i.e. DC optimizer, MPPT, Distributed MPPT, string inverter, microinverter, etc. Most of the work is carried out on adaptive PV array reconfiguration with different optimization algorithm. Even if these methods are effective, it has limitation i.e. large numbers of power electronics switches with complicated control technique is required.

\section{Conclusion}

The outcome of this paper is a qualitative review of the different solutions over effects of partial shading condition in PV system. The low cost solution is bypass diode, but power loss will be more and it reduces conversion effecicncy of the system. Adaptive PV configuration is also a good solution which comes with less losses as compared to other methods but there is a complexicity with operation of a number of switches. In power electronic methods (i.e. use of MPPT, DC-DC converter, etc.), the losses are moderate as compare to above methods. For minimising these losses there is a need to work on reduction of electronics component and also look the smart solar panels which will take care of their performance during shadow condition.

The overall observsation is that, any of the above methods can be selected on the basis of system installation cost, cost of generation, losses, pay back period etc. These cost should be within the limit of economic operation of solar power plant.

\section{References}

[1] Hua C., J. Lin, and C. Shen. "Implementation of a DSP-controlled photovoltaic system with peak power tracking," IEEE Trans. Ind. Electron. Vol. 45, no1, pp99-107,1998.

[2] Vieira J. A. B. and A. M. Mota, "Maximum power point tracker applied in batteries charging with PV panels," IEEE International Symposium on Industrial Electronics, ISIE, Cambridge, pp. 202-207, 2008.

[3] Liu Y. H. and J. W. Huang, "A fast and low-cost analog maximum power point tracking method for low power photovoltaic system," Sol. Energy Vol 85, no 11, pp 2771-2780, 2011.

[4] Indu Rani B.,G. Saravana Ilango, and C. Nagamani, "Power flow management algorithm for photovoltaic systems feeding DC/AC loads” Renewable Energy, Elsevier vol 43, pp 267-275, 2012.

[5] Patel H, Agarwal V., "MATLAB-based modeling to study the effects of partial shading on PV array characteristics", IEEE Transactions Energy Conversion, Vol 23, pp302-310, 2008.

[6] Zhang J. Qi, Y., and Y. Chen, "Modeling and maximum power point tracking (MPPT) method for PV array under partial shade conditions" IEEE Trans. Renewable Energy, Vol. 66, pp 337-345, 2014.

[7] Young J. -Hyok, J. Doo-Yong, W. Chung-Yuen, L. Byoung-Kuk, and K. Jin-Wook, "A real maximum power point tracking method for mismatching compensation in PV array under partially shaded conditions," IEEE Trans. Power Electron. Vol 26, no. 4, pp 1001-1009, 2011.

[8] Koutroulis E., and F. Blaabjerg, "A new technique for tracking the global maximum power point of PV arrays operating under partial-shading conditions," IEEE Journal of Photovoltaics Vol. 2 no.2, pp184 190, 2012.

[9] Woytea A., J. Nijsa, and R. Belmansa (2003), "Partial shadowing of photovoltaic arrays With different system configurations: Literature review and field test results," Solar Energy, Elsevier vol. 74, no.3, 217-233, 2003.

[10] Karatepe E., M. Boztepe, and M. C,Olak, "Development of a suitable model for characterizing photovoltaic arrays with shaded solar cells," Solar Energy Vol 81, pp 977-992.2007.

[11] Smita Pareek, Ratna Dahiya, "Output Power Maximization of Partially Shaded 4*4 PV field by Altering its Topology", Elsevier Energy Procedia Vol 54, pp116 - 126, 2014.

[12] Indu Rani B., G. Saravana Ilango, Chilakapati Nagamani, "Enhanced Power Generation From PV 
Array Under Partial Shading Conditions by Shade Dispersion Using Su Do Ku Configuration”, IEEE, Trans, Sustainable Energy, Vol 4, pp 594-601, 2013.

[13] Fei Lu, Siyu Guo, Timothy M. Walsh, Armin G. Aberlea, "Improved PV Module Performance Under Partial Shading Conditions", Elsevier Energy Procedia vol 33, pp 248 - 255, 2013

[14] Velasco G, J. J. Negroni, F. Guinjoan, and R. Piqué, "Energy generation in PV grid-connected systems: A comparative study depending on the PV generator configuration", IEEE International. Symp. Industrial Electronics, Vol. 3, pp 1025-1030, 2015.

[15] Solórzano, J., \& Egido, M. A., "Hot-spot mitigation in PV arrays with distributed MPPT (DMPPT)", Solar Energy, Vol. 101, pp 131- 137, 2014.

[16] Daliento, S., Mele, L., Bobeico, E., Lancellotti, L., \& Morvillo, P., “Analytical modelling and minority current measurements for the determination of the emitter surface recombination velocity in silicon solar cells", Solar energy materials and solar cells, Vol. 91, pp 707-713, 2007.

[17] Mahmoud Dhimish, Violeta Holmes, Bruce Mehrdadi, Mark Dales, and Peter Mather, "Output Power Enhancement for Hot Spotted Polycrystalline Photovoltaic Solar Cells”, IEEE. TRANS. Vol 18, pp 3745. 2017.

[18] Carannante G., C. Fraddanno, M. Pagano, and L. Piegari, "xperimental performance of MPPT algorithm for photovoltaic sources subject to inhomogeneous insolation", IEEE Trans. Ind. Electron. Vol 56, pp 4374-4380, 2009.

[19] Mei Q. , M. Shan, L. Liu, and J. M. Guerrero, “A novel improved variable step-size incrementalresistance MPPT method for PV systems”, IEEE Trans. Industrial. Electronics, Vol. 58, pp 2427-243, 2011.

[20] Jieming Ma, Member, Xinyu Pan, Ka Lok Man, Xingshuo Li, Huiqing Wen, Tiew On Ting, "Detection and Assessment of Partial Shading Scenarios on Photovoltaic Strings", IEEE, Trans, Ind. Applications Vol 6, pp 6279-6289, 2018.

[21] Mohammad Amin Ghasemi, Hossein Mohammadian Forushani, Mostafa Parniani , "Partial Shading Detection and Smooth Maximum Power Point Tracking of PV Arrays under PSC", IEEE, Trans, Power Electronics, Vol 31, pp 6281 - 6292, 2016."

[22] Femia N., G. Lisi, G. Petrone, G. Spagnuolo, and M. Vitelli, "Distributed maximum power point tracking of photovoltaic arrays: Novel approach and system analysis”, IEEE Trans. Ind. Electron., Vol 55, no. 7, pp 2610-2621, 2008.

[23] Gao L., R. A. Dougal, S. Liu, and A. P. Iotova, "Parallel-connected solar PV system to address partial and rapidly fluctuating shadow conditions", IEEE Trans. Ind. Electron. Vol 56, pp 1548-1556, 2009.

[24] Busquets S.-Monge, J. Rocabert, P. Rodriguez, S. Alepuz, and J. Bordonau, “ Multilevel diode-clamped converter for photovoltaic generators with independent voltage control of each solar array", IEEE Trans. Ind. Electron., Vol 55. pp 2713-2723, 2008.

[25] Bratcu A. I., I. Munteanu, S. Bacha, D. Picault, and B. Raison, "Cascaded DC-DC converter photovoltaic systems: Power optimization issues", IEEE Trans. Ind. Electron,. Vol 58, pp 403-411. 2011.

[26] Vaishnavi P. Deshpande, Sanjay B. Bodkhe, "Solar PV array reconfiguration using Ant Colony Optimisation for maximum power extraction under partial shading conditions" Int. Journal of Engineering Research and Application, vol. 7, Issue 9, 21-28, 2017. 